\title{
WHAT SECONDARY PREDICATES IN RUSSIAN TELL US ABOUT THE LINK BETWEEN TENSE, ASPECT AND CASE*
}

\author{
Kylie Richardson \\ Harvard University
}

\begin{abstract}
In this paper I show that the different case marking possibilities on predicate adjectives in depictive secondary predicates in Russian constitute the uninterpretable counterpart of the interpretable tense and aspect features of the adjective. Case agreement entails that the predicate adjective is non-eventive, i.e., it occurs when the event time of the secondary predicate is identical to the event time of the primary predicate. The instrumental case, however, entails that the secondary predicate is eventive: some change of state or transition occurred prior to or during the event time of the primary predicate. I claim that case agreement occurs in conjoined tense phrases in Russian, while the instrumental case occurs in adjoined aspectual phrases. In English, secondary predication is sensitive both to the structural location of its antecedent and to the event structure of the primary predicate. I suggest that depictives with subject antecedents in English are true adjunction structures, while those with direct object antecedents occur in a conjoined aspectual phrase. This hypothesis finds support in the different movement and semantic constraints in conjunction versus adjunction phrases in both English and Russian.
\end{abstract}

\section{Introduction}

In this paper I address a classic problem of Russian grammar, namely the different case marking possibilities found on predicate adjectives like examples (1)-(5). ${ }^{1,2}$

\footnotetext{
* I am extremely grateful for the unrelenting patience of my Russian native informants who willingly gave up many hours of their precious time to answer my never-ending questions. Thanks go especially to Polina Rikoun, Ekaterina Dianina, Alfia Rakova, Vadim Platonov, Alexander Spektor and Misha Dobroliubov. Thanks also go to Patricia Chaput, Michael Flier, Catherine Chvany, Sue Brown, Rachel Platonov, Stephanie Harves and the participants in the Slavic linguistics colloquia at Harvard. My ideas in this paper were also influenced by comments made by David Pesetsky in his graduate course on tense and aspect in syntax at MIT, cotaught with Sabine Iatridou in the fall of the 2001-2002 academic year. The usual disclaimers apply.

${ }^{1}$ In Russian every noun and adjective is marked with one of six morphological case endings. I use the following shorthand for the different cases: $\mathrm{NOM}=$ nominative; $\mathrm{ACC}=$ accusative; $\mathrm{GEN}=$ genitive; DAT $=$ dative; PREP $=$ prepositional; INSTR $=$ instrumental.

${ }^{2}$ Russian is a language in which scrambling is common and appears to be cost-free. There is, however, a simple test to determine whether a predicate adjective with case agreement is predicative and not attributive. Attributive adjectives cannot modify object pronouns in Russian, as the examples below show.

(i)

$$
\text { * Milicija privela p'janogo ego domoj. }
$$$$
\text { Police brought drunk-ACC him-ACC home }
$$ 
Vadim vernulsja iz bol'nicy zdorovyj/ zdorovym.

Vadim-NOM returned from hospital healthy-NOM/cured-INSTR

'Vadim returned from the hospital healthy/cured.'

Ja zakazala $\quad$ rybu $_{\mathrm{i}} \quad$ syruju $_{\mathrm{i}} / \quad$ syroj $_{\mathrm{i}}$.

I ordered fish-ACC raw-ACC/ raw-INSTR

'I ordered the fish raw'.

My tancuem p'janye/ p'janymi.

We-NOM dance drunk-NOM/ drunk-INSTR

'We are dancing drunk/we dance drunk'.

$$
\begin{aligned}
& \text { Ja pokupaju banany }{ }_{i} \quad \text { spelye }_{i} / \text { spelymi }{ }_{i} \text {. } \\
& \text { I-NOM buy bananas-ACC ripe-ACC/ ripe-INSTR } \\
& \text { 'I am buying the bananas ripe/I buy (my) bananas ripe'. }
\end{aligned}
$$

$$
\begin{aligned}
& \text { Ja pozvonila emu } \text { em }_{\mathrm{i}} \text { 'janomu } \mathrm{i}_{\mathrm{i}} \quad{ }^{*} \mathrm{p}^{\prime} \text { janym }_{\mathrm{i}} \text {. } \\
& \text { I-NOM phoned him-DAT drunk-DAT/ *drunk-INSTR } \\
& \text { 'I phoned him (and he was) drunk'. }
\end{aligned}
$$

These constructions are all depictive small clauses. They are commonly referred to as adjunct small clauses, since the predicate adjective is not obligatory. In Russian, the only difference between the minimal pairs in examples (1)-(4) above is the case ending on the predicate adjective. Each example, however, has a different interpretation. In example (1) case agreement (by which I mean that the predicate adjective exhibits the same case marking as its antecedent), entails a description of Vadim's state at the point in time at which he returned home, i.e., the event time of the secondary predicate is identical to that of the primary predicate. The predicate adjective with instrumental case, however, entails that Vadim's healthy state is the result of a change of state at some point prior to the event time of the primary predicate. The different English translations capture this change of state versus its absence in these examples. ${ }^{3}$ In example (2) the instrumental case entails a comparison between ordering the fish in its raw state versus, say, its cooked state. The adjective with case agreement does not entail any sort of comparison and simply describes the state of the fish at the time of the ordering event. In examples (3) and (4) the predicate adjectives with case agreement lend a progressive interpretation to the verb phrase, while the predicate adjectives with instrumental case lend a habitual or generic interpretation. In example (5) the verb takes an obligatory quirky case marked objectthe dative - and case agreement on the predicate adjective is obligatory.

In this paper, I will show that the case agreement versus instrumental dichotomy is intimately connected to the event structure of both the primary and secondary

(ii)
Milicija privela ego
domoj p'janogo.
Police brought him-ACC home drunk-ACC
(Example taken from Nichols 1981: 156)

The examples in this paper have been tested with pronominal antecedents.

${ }^{3}$ I thank Asya Pereltsvaig for discussing this example and similar examples with me. 
predicate. ${ }^{4}$ I will claim that the different case marking possibilities constitute the uninterpretable counterpart of interpretable tense and aspect features in secondary predicate constructions. Case agreement on predicate adjectives is the uninterpretable counterpart of interpretable tense, while the instrumental case is the uninterpretable counterpart of interpretable aspect. This work thus builds on recent analyses in the literature on $\mathrm{C} /$ case that address the link between C/case and tense or aspect (see, for instance, Krifka 1991, Ramchand 1997, Kiparsky 1998, Pesetsky and Torrego 2000, and Svenonius 2001).

The format of this paper is as follows. Section one provides a brief discussion of the role of Case in syntax. Section two contains the body of the paper. It outlines the distribution of depictive small clauses in both English and Russian, and provides a syntactic account for the aspectual constraints on the formation of these constructions in English and on their different case marking possibilities in Russian. Section three provides an analysis of predicate adjectives with obligatory case agreement, namely those adjectives with "quirky" case marked antecedents, those with an indirect internal (dative) argument antecedent, and those with an antecedent contained within a prepositional phrase. Section four is the conclusion.

\section{The Role of Case in Syntax}

Case is generally considered a formal feature that must be checked and deleted prior to the interfaces (PF and LF). The system of feature checking developed by Chomsky $(1995,1998)$, among others, states that pairs of features exist in which only one member of the pair is semantically interpretable, while the other is uninterpretable. Feature checking occurs when an uninterpretable feature is matched with an interpretable counterpart within a limited search domain. This checking of features is required before a derivation is sent off to the interfaces, i.e., uninterpretable features must be eliminated for legibility conditions to be satisfied. As Svenonius (2001) notes, in this system we are left with a curious state of affairs, in that the other formal features postulated to account for grammatical processes generally have some semantic content. Take, for instance, the number feature on subject noun phrases. This number feature has a semantic value or interpretable feature in that it indicates the plural or singular nature of the noun phrase. The number feature on the finite verb, however, as manifested in agreement morphology, does not have a semantic value - it is uninterpretable - since the plurality or singularity of the agreement morphology does not bear any semantic value of the verb independently of the semantic value of the subject. When these uninterpretable and interpretable features match, the uninterpretable one is formally deleted (though its morphological manifestation remains). In Chomsky's system of feature checking, however, Case does

\footnotetext{
${ }^{4}$ This work differs significantly from earlier work (Richardson in press) in which I claimed there was a link between the case marking on predicate adjectives in depictives and grammatical aspect. My earlier work attempted to link the distribution of depictives with byt' 'be' small clauses. The distribution of case agreement versus the instrumental in byt' constructions does appear to be sensitive to grammatical aspect, as Matushansky (2000a, 2000b) convincingly shows. The different case marking possibilities with depictive small clauses in Russian, however, is sensitive to the event structure of the predicate adjective and to the event structure of the primary predicate, not grammatical aspect. Byt' small clauses therefore constitute a different phenomenon.
} 
not have an interpretable counterpart, but instead is an anomaly subject to the descriptive stipulation that unlike other grammatical features, it is "the pure uninterpretable feature par excellence" (Chomsky 1995: 278-279; 2000: 102, 119).

The existence of pure uninterpretable features complicates an otherwise "minimalist" approach to feature checking. As Pesetsky and Torrego note, the most "minimalist" possible position would hold that such features do not exist (2000: 7). Recently there has been a move to bring Case features more in line with other grammatical features. Scholars are beginning to seek a connection between uninterpretable Case features and interpretable grammatical features. Such a connection seems to exist between the case of noun phrases and tense or aspect. Pesetsky and Torrego (2000), for instance, claim that nominative case is the uninterpretable manifestation of interpretable tense features. Svenonius (2000) argues that in Icelandic accusative and dative case marking alternations are directly related to the event structure of the verb phrase in which they occur. Kiparsky (1998) claims that Finnish marks unbounded events with partitive case on the direct object, bounded ones with accusative case. Ramchand (1997) has also shown a connection between aspect and object case in Bengali and in Scottish Gaelic.

This work on case is exciting in a number of ways. First, we are finally moving towards an investigation of the role of morphological case in syntax, and, second, with a shift in attention on morphological case marking, the time is ripe for figuring out the nature of case marking on predicate adjectives in Russian, a problem that has long stumped linguists working on this phenomenon in the Slavic languages. In this paper, I will provide further evidence that the elimination of purely uninterpretable features in syntax is a step in the right direction (see, for instance, Svenonius 2001). I will show that the Case features on predicate adjectives in Russian, like the number features on verbs, are the uninterpretable counterpart of the interpretable tense or aspect features on the predicate adjective.

\section{Depictive Small Clauses in English and Russian}

\subsection{Against the Stage-level Constraint on Depictives}

It has been suggested that a predicate adjective can only occur in depictive small clauses if it is a so-called Stage-level adjective-an adjective that denotes a more temporary characteristic of its antecedent. So-called Individual-level predicate adjectivesadjectives that denote more permanent characteristics of their antecedents - are claimed to be ungrammatical (see, for instance, Rapoport 1991, 1993. On the Stage- versus Individual-level contrast see Carlson 1977), hence the grammaticality in both Russian and English of examples like (7) below, but the ungrammaticality of (6).

$$
\begin{array}{lll}
\begin{array}{l}
\text { *Ivan } \\
\text { *Ivan-NOM }
\end{array} & \begin{array}{l}
\text { prišel umnyj/ } \\
\text { arrived intelligent-NOM/ }
\end{array} & \begin{array}{l}
\text { umnym. } \\
\text { intelligent-INSTR. }
\end{array} \\
\text { Ivan } & \begin{array}{l}
\text { prišel p'janyj/ } \\
\text { arrived drunk-NOM/janym. }
\end{array} & \text { p'junk-INSTR. }
\end{array}
$$


It is not clear how one might capture this so-called Individual- versus Stage-level description in the syntax. I will show that this distinction is unnecessary to account for the distribution of depictive small clauses. The distribution of depictives in English and Russian, for instance, suggests that the correct generalization is one that makes reference to the event structure of the predicate adjective. That is, only eventive predicate adjectives can occur in depictives, hence the grammaticality of (7), but ungrammaticality of (6). The adjective umnyj 'intelligent' is stative, and thus is devoid of event structure. The adjective $p$ 'janyj 'drunk', however, is eventive, it entails the transition from one state to another. Unless the context provides a stative adjective with an eventive interpretation (see the examples in McNally 1994, for instance), it will be ungrammatical in depictive small clauses. The distinction between whether an adjective is interpreted as eventive or not plays a crucial role in the case marking possibilities on secondary predicates in Russian. The case marking possibilities have nothing to do with whether an adjective is interpreted as a more temporary or permanent quality of its antecedent, as will soon become clear. We can capture the aspectual constraints on depictives syntactically by positing the existence of aspectual phrases in primary and secondary predicates, as I will show shortly.

It is necessary at this point to clarify some terminology, namely what sort of aspect plays a role in the structure of depictives. There are essentially two phenomena that fall under the rubric of aspect: grammatical aspect and event structure. Russian, for instance, has a rich system of verbal aspectual morphology that manifests itself in a twoway split between the imperfective and perfective aspect. This type of aspect has been referred to in the literature as grammatical, morphological, viewpoint or outer aspect. I will refer to this aspect as grammatical aspect. It is the aspect that specifies how an event is viewed. In Russian, perfective actions are limited in time, and are perceived as a unit, without any importance attached to their duration or internal constituency. Imperfective actions, however, focus on the internal constituency of an event. They are unbounded, and used for situations that focus on an action in progress, in duration, or in repetition. Imperfective verbs in Russian never express single unitary actions with focus on completion or accomplishment.

Aspect is also used in the literature to refer to types of actions. This type of aspect has been referred to as semantic, lexical, situation, Vendlerian, inner aspect, or event structure, eventuality, Aktionsarten. I will refer to this aspect as event structure. Event structure is typically used to specify whether a verb and its arguments is perceived as a state, activity, accomplishment or achievement. These four classes are based on Vendler's 1957 distinctions. States have no internal structure and do not change during the span of time over which they are true (e.g., John loves Betty). Activities are ongoing events with internal change and duration, but do not necessarily have an endpoint (Bill walked along the river for an hour). Accomplishments are events with duration and an obligatory temporal endpoint (Bill consumed the pineapple in two minutes). Achievements have an instantaneous culmination or endpoint and are without duration (Jake reached the summit in five minutes).

I see no reason why adjectives, like verbs, do not also have event structure. Adjectives are traditionally classified as [+nominal], [+verbal] elements. The traditional breakdown of grammatical categories is as follows $([+\mathrm{N}]$ means that the category contains a nominal element, $[+\mathrm{V}]$ means that it contains a verbal element). 
(8)

$\begin{array}{lll}\text { Nouns } & \text { Verbs } & \text { Adjectives } \\ {[+\mathrm{N}]} & {[-\mathrm{N}]} & {[+\mathrm{N}]} \\ {[-\mathrm{V}]} & {[+\mathrm{V}]} & {[+\mathrm{V}]}\end{array}$

Prepositions

$[-\mathrm{N}]$

$[-\mathrm{V}]$

Like nouns, adjectives in Russian have case morphology. Based on the breakdown in (8), it follows that, like verbs, adjectives also have event structure and tense features. ${ }^{5}$ It is difficult, however, to see how Vendler's terminology could carry over to a description of the event structure of adjectives, except perhaps the concept of a state. Pustejovsky's (1991) breakdown of the subeventual structure of verbs, however, is able to capture intuitions about the event structure of adjectives. Pustejovsky (1991) claims that events have internal structure that can be decomposed into smaller parts. He identifies three temporal subperiods - initial, internal, and final - that identify three underlying properties of event classification. He uses these three temporal periods to define three event typesstates, processes and transitions. His breakdown of event types is as follows.

(9) State (S): a single event, which is evaluated relative to no other event.

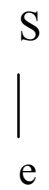

(10) Process (P): a sequence of events identifying the same semantic expression.

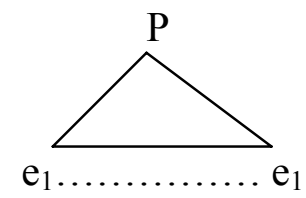

(11) Transition (T): an event identifying a semantic expression which is evaluate relative to its opposition.

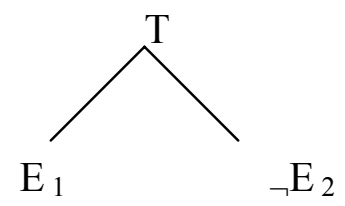

$\mathrm{E}$ in the structure for a transition stands for any event type, although transitions generally decompose into a process with a culminating state. Pustejovsky thus collapses achievements and accomplishments into transitions. In Pustejovskian terms, an adjective like 'intelligent' would be a state and thus non-eventive in the sense that it does not involve any sort of transition in its event structure, i.e., it is not evaluated relative to any other event. In the absence of any mitigating circumstances, one is born intelligent and dies intelligent. An adjective like 'drunk', however, is eventive: it entails the transition

\footnotetext{
${ }^{5}$ Support for the hypothesis that adjectives encode verbal properties like tense and aspect comes from languages like Japanese in which both adjectives and verbs are conjugated.
} 
from one state to another, and it is evaluated relative to its opposition. Only the eventive adjective is licensed in depictives. I will now show that the [+verbal] properties - tense and aspect - play a crucial role in the case marking possibilities on predicate adjectives in Russian and on the structural properties of depictives in English.

\subsection{Constraints on the Distribution of Depictives: The data}

In English, secondary predication is sensitive to the event structure of the verb phrase when the predicate adjective has an object antecedent. With subject antecedents this sensitivity disappears. Rapoport (1999) claims that secondary predicates with object antecedents can only occur with achievements and accomplishments, while subjects can occur with achievements, accomplishments and activities. ${ }^{6}$ Thus, in Pustejovskian terms, a predicate adjective with an object antecedent can only occur with an eventive verb phrase, namely a transition. Consider the following examples.

$$
\begin{aligned}
& \text { John ate the meati } \text { raw }_{\mathrm{i}} \text {. } \\
& \mathrm{John}_{\mathrm{k}} \text { pushed Bill } \text { drunk }_{*_{\mathrm{i}} \mathrm{k}} .
\end{aligned}
$$

Bill sliced the bread $_{\mathrm{i}}$ warm $_{\mathrm{i}}$. $\mathrm{John}_{\mathrm{k}}$ chased Betty drunk $_{*}{ }_{\mathrm{i} / \mathrm{k}}$.

In (14) and (15) the predicate adjective can only refer to the subject 'John'. 'Push' and 'chase' are not transitions, thus, object reference is not possible. It may seem counterintuitive to think of 'push' and 'chase' as activities or processes. They are, however, activities in the sense that they cannot be modified by in $x$ time. Dowty (1979) claims, for instance, that verb phrases in which the modifier is in $x$ time are accomplishments, while verb phrases where the modifier is for $x$ time are activities. If we

\footnotetext{
${ }^{6}$ Like Rapoport (1999), I will not discuss the structure of secondary predicates with statives like 'Jones preferred her coffee black', which, as Rapoport notes (pg. 654) have different properties than the depictive constructions under analysis. The claim that statives behave differently from "true depictives" also seems to hold for so-called propositional statives (this term is taken from Timberlake 1982). In propositional stative constructions the eventive constraint on predicate adjectives with object antecedents does not hold, as the following examples show.
}

(i) Jake drinks coke warm.

(ii) Alli eats meat raw.

The VPs in these examples are not achievements or accomplishments, yet the secondary predicate is still licit with an object antecedent. The different movement constraints on propositional statives also suggest that these constructions are different from true depictives. Consider the following examples.

(iii) Coke warm is what Jake drinks.

(iv) ? The coke warm is what Jake drank.

(v) Meat raw is what Alli eats.

(vi) ? The meat raw is what Alli ate.

Movement of the NP antecedent and the secondary predicate in the stative examples are more acceptable than in the eventive examples. I will not discuss the distribution and behavior of statives. Note, however, that under my analysis, the different behavior of statives is part and parcel of a larger phenomenon: small clauses come in many different flavors. 
apply Dowty's test to these examples, 'push' and 'chase' are activities (i.e., they do not encode a transition) while 'ate' and 'slice' can be both accomplishments and activities.

John pushed Bill for an hour/*in an hour. John chased Bill for an hour/*in an hour. John ate the meat for an hour/in an hour. John sliced the bread for a minute/in a minute.

Notice that once we add additional argument structure to 'push' and 'chase', changing their event structure class from activities to accomplishments (processes to transitions), they are much more acceptable. In the following examples, for instance, the addition of the prepositional phrases 'into the lake' and 'into the ditch' change the event structure of the verbs and the secondary predicate is licit with an object antecedent.

John pushed Bill ${ }_{\mathrm{i}}$ into the lake drunk $\mathrm{i}_{\mathrm{i}}$

John chased Betty $y_{i}$ into the ditch drunk $k_{i}$.

It is important to note that the crucial factor determining whether the secondary predicate is possible is whether the verb phrase in its base form is a transition. How the action is then viewed-imperfectively, perfectively or progressively-is not relevant. Thus, a predicate adjective with an object antecedent is possible with progressives, provided the verb phrase in its base form is a transition, i.e., that it is a "propositional process or activity", is inconsequential, as the following examples show.

Kate is buying the meat raw.

?/* Kate is buying meat raw.

In the absence of a highly defined context, the transition (example (22)) is more acceptable than the process (example (23)) with a depictive small clause. Thus, in English both the primary and secondary predicate in depictive small clauses with object antecedents must be eventive, i.e., "likes occur with likes." Predicate adjectives with subject antecedents, however, are not sensitive to the event structure of the primary predicate, as examples (14) and (15) illustrated.

Unlike English, in Russian a secondary predicate can occur with any verb phrase, regardless of its event structure. A predicate adjective is grammatical with an object antecedent, for instance, with activity or process verbs like 'push', as (24) shows.

$$
\begin{array}{lll}
\text { Ja tolknula } & \text { Ivana }_{\mathrm{i}} & \text { p'janogo } \\
\text { I pushed } & \text { Ivan-ACC } & \text { drunk-ACC }
\end{array}
$$

Like English, however, a sensitivity to event structure exists in depictives. This sensitivity, however, manifests itself in the different case marking possibilities on the predicate adjective. Take example (1) at the beginning of this paper, for example, repeated below as (25). 
What Secondary Predicates in Russian Tell Us

about the Link between Tense, Aspect and Case

$$
\begin{aligned}
& \text { Vadim vernulsja iz bol'nicy zdorovyj/ zdorovym. } \\
& \text { Vadim-NOM returned from hospital healthy-NOM/cured-INSTR } \\
& \text { 'Vadim returned from the hospital healthy/cured.' }
\end{aligned}
$$

The verb vernut'sja 'to return' is a transition. There is a strong preference amongst native speakers for the secondary predicate to occur with instrumental case marking when the primary predicate is a transition. Case agreement is, however, possible, but it entails a non-eventive interpretation of the adjective (although, of course, the adjective is still eventive in its base form), resulting instead in the interpretation that the event time of the secondary predicate is identical to that of the primary predicate. As a result, constructions in which the secondary predicate has instrumental case marking encode two events - the event of the primary predicate and the event of the secondary predicate. In (25), for instance, the instrumental case on the secondary predicate entails that at some point in the past, Ivan became healthy, he then returned home in this new healthy state. Constructions in which the secondary predicate has case agreement encode one event, since the event time of both the primary and secondary predicate is identical. Consider another example with a primary predicate that denotes a transition.

$$
\begin{aligned}
& \text { Polina }_{\mathrm{i}} \text { s"jela poslednij kusoček jabloka } \\
& \text { Polina-NOM ate last piece-ACC apple-GEN } \\
& \text { p'janaja } \mathrm{i}_{\mathrm{i}} \quad \text { p'janoj } \mathrm{j}_{\mathrm{i}} \\
& \text { drunk- NOM/drunk-INSTR } \\
& \text { 'Polina ate the last piece of the apple drunk'. }
\end{aligned}
$$

The predicate adjective with nominative case agreement entails that for the entire eating of the apple event, Polina was drunk. The predicate adjective with instrumental case marking entails that Polina became drunk at some point before or during the eating event. One can imagine a situation, for instance, in which Polina is eating the apple and swigging away on a bottle of vodka at the same time. By the time she eats the last little piece of the apple, she has become drunk. Only the instrumental case is licit in this scenario.

It has been claimed that only adjectives that denote a temporary state can occur in the agreeing form in depictives (Hinterhölzl 2001: 103). Hinterhölzl (2001) states, for instance, that adjectives like spelyj 'ripe' and syroj 'raw' are ungrammatical in depictives in the agreeing form because they do not denote temporary properties. He provides examples like (27) to support his hypothesis:

$$
\begin{array}{lll}
\text { On } & \text { sobral slivy } & \text { spelymi } \\
\mathrm{He} / & \text { plucked plums ripe-INSTR/ } & { }^{*} \text { spelye }_{\mathrm{i}} . \\
\text { *ripe-NOM. }
\end{array}
$$

This generalization, however, is not correct. Take examples (2) and (4) at the beginning of this paper, for instance, repeated below as (28) and (29). Notice that both case agreement and instrumental case marking are possible on the predicate adjectives spelyj 'ripe' and syroj 'raw' in these examples. 


$$
\begin{aligned}
& \text { Ja pokupaju } \text { banany }_{\mathrm{i}} \quad \text { spelye }_{\mathrm{i}} / \mathrm{\text {spelymi } _ { i } .} \\
& \text { I-NOM buy } \\
& \text { 'I am buying the bananas ripe/I buy (my) bananas ripe'. }
\end{aligned}
$$

$\begin{array}{llll}\text { Ja zakazala } & \text { rybu }_{i} & \text { syruju }_{i} / & \text { syroj }_{i} . \\ \text { I ordered } & \text { fish-ACC } & \text { raw-ACC/ } & \text { raw-INSTR } \\ \text { 'I ordered the fish raw'. } & & \end{array}$

Native speakers claim that a predicate adjective with instrumental case marking in examples like (29) entails an implicit comparison between the state denoted by the predicate adjective with an alternative state, while case agreement entails no such comparison. The question that then arises is why case agreement is acceptable in this example, but not in (27), and why case agreement is less preferred in many other examples, like (30) below.

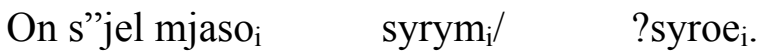

$$
\begin{aligned}
& \text { He ate meat-ACC raw-INSTR/ ?raw-ACC } \\
& \text { 'He ate the meat raw.' }
\end{aligned}
$$

First, in Hinterhölzl's example (27), the primary predicate is a transition. Transitions favor instrumental case marking on the predicate adjective, since transitions often lend an eventive interpretation to the predicate adjective, and there is a tendency for "likes to occur with likes." 7 More importantly, however, recall Pustejovsky's (1991) definition of a state versus a transition ((9) and (11) above): states are evaluated relative to no other event, while transitions are evaluated relative to an opposition. If the instrumental case is used with transitions, i.e., eventive predicate adjectives, while case agreement is used with non-eventive adjectives, then the association of the adjective with instrumental case marking with a comparison to some other state is predicted by the very definition of transitions: they are evaluated relative to an opposition. With stative morphology-case agreement - as expected, no such comparison will exist, since states are evaluated relative to no other events.

\footnotetext{
${ }^{7}$ Hence the grammaticality of psychological states in the instrumental case in examples like:
}

(i) On prišel grustnym. He-NOM arrived sad-INSTR

And similarly the possibility for instrumental case marking on psychological states if information is added which specifies that the predicate adjective entails an eventive interpretation. Compare, for instance, (ii) and (iii) below.

(ii) Vadim čitaet grustnyj $/ *$ grustnym Vadim-NOM reads sad-NOM/*sad-INSTR

(iii) Vadim tol'ko čitaet grustnym/?grustnyj. Vadim-NOM only reads sad-INSTR/?sad-NOM

The addition of the adverb tol'ko 'only' opens the door to an eventive interpretation of the stative adjective. 
Pragmatic notions like expectation also play a role in the case marking of the predicate adjective in examples like (27)-(30). ${ }^{8}$ If, for instance, there is nothing contrary to expectation about, say, ordering fish in its raw state, agreement will be possible, hence the case agreement on the predicate adjective in (29), i.e., the state of the fish is evaluated relative to no other event or state. If a state is perceived as unexpected, however, the instrumental case will occur on the predicate adjective, hence the preference for the instrumental case in example (30): the raw state of the meat is evaluated relative to its opposition, cooked meat (the expected state in which one eats meat). Often, just the addition of a depictive adjective to a construction entails a degree of unexpectedness. Why state, for instance, that one gathered the plums ripe if comparison with some other state is not implied? Why not simply state that one gathered the plums? This degree of unexpectedness favors the instrumental case on the predicate adjective, since it opens the door to a comparison with some other state. This hypothesis is supported by examples like the following in which both case agreement and the instrumental case are possible on the predicate adjective.

$\begin{array}{lll}\text { Ja voz'mu ego } & \text { živogo } / & \text { živym }_{\mathrm{i}} . \\ \text { I-NOM take him-ACC } & \text { alive-ACC/ } & \text { alive-INSTR } \\ \text { 'I will take him alive'. } & & \\ \text { (Richardson in press) } & & \end{array}$

There is no broken expectation entailed in the predicate adjective in this example. We expect that someone might be taken alive, thus, non-eventive case marking (case agreement) is possible. As expected, the instrumental case on the predicate adjective in this example entails a comparison between two different states: 'I will take him alive, not dead', or 'I won't kill him in the process of taking him'. Context and pragmatic notions like expectation therefore play a crucial role in whether case agreement is possible on a predicate adjective.

Consider now example (28). First of all, a predicate adjective that occurs with verbs that denote processes (or activities) may exhibit both case agreement with its antecedent or the instrumental case in Russian. As expected, case agreement entails that the event time of the predicate adjective is identical to the event time of the primary predicate. The instrumental case on the adjective entails either that a transition occurred prior to or during the event time of the primary predicate. In example (28), case agreement on the predicate adjective entails that 'I am buying the bananas ripe right now', while the instrumental case entails 'I buy (my) bananas ripe (in general).' That is, the different interpretations that the different case endings manifest lead to a progressive interpretation of an activity or process versus a habitual or generic interpretation. This generalization is also true of example (1) at the beginning of this paper, repeated below as (32).

My tancuem $\quad \begin{gathered}\text { p'janye/ } \\ \text { drunk-NOM/ } /\end{gathered}$
We-NOM drunk-INSTR
'We are dancing drunk/we dance drunk'.

\footnotetext{
${ }^{8}$ I thank Patricia Chaput for suggesting to me that "expectation" could play a role in the case marking of secondary predicates in Russian.
} 
The progressive interpretation of the primary predicate is entirely in keeping with the generalization that the event time of a predicate adjective with case agreement is identical to the event time of the primary predicate, while the habitual interpretation follows naturally from the interpretation of the predicate adjective with instrumental case marking as a transition, i.e., we + dance $\left(3^{\text {rd }}\right.$ person plural, present tense $)+$ (we are) drunk $\rightarrow$ 'we are dancing drunk', while we + dance $\left(3^{\text {rd }}\right.$ person plural, present tense $)+$ (we got) drunk $\rightarrow$ 'we dance drunk' (we dance having become drunk).

That the event structure of the primary predicate plays a role in the different case marking possibilities on the predicate adjective in the secondary predicate is seen most acutely with verbs that denote processes, i.e., activity verbs. This fact is most evident in the case marking possibilities on the predicate adjective in nonfinite clauses. It is generally assumed that case agreement is impossible in nonfinite clauses unless the antecedent for the predicate adjective is a subject in the higher finite clause (Franks 1995, and Richardson in press). This generalization has lead some to posit various subject and object asymmetries in secondary predicates in Russian. Case agreement in nonfinite clauses with object antecedents $i s$, however, possible. The event structure of the primary predicate is the crucial factor that affects the choice of one case ending over another: case agreement is possible with activity/process verbs, the instrumental case is preferred (sometimes obligatory) with transitions. The following examples, for instance, all have activity verbs in the nonfinite clause. Notice that case agreement is possible on the secondary predicate in the nonfinite clause, irrespective of the structural location of the overt antecedent.

Nominative subject antecedent ${ }^{9}$

$\begin{array}{llll}\text { Ja prišla PRO } & \begin{array}{l}\text { tancevat' } \\ \text { to-dance }\end{array} & \begin{array}{l}\text { golaja/ } \\ \text { naked-NOM/ }\end{array} & \text { goloj. } \\ \text { I-NOMed-INSTR }\end{array}$

Accusative direct internal object antecedent

$$
\begin{aligned}
& \text { Ja poprosila } \mathrm{ego}_{\mathrm{i}} \quad \mathrm{PRO}_{\mathrm{i}} \text { tancevat' gologo } / \text { golym } \mathrm{i}_{\mathrm{i}} \text {. } \\
& \text { I-NOM asked him-ACC to-dance naked-ACC/naked-INSTR }
\end{aligned}
$$

Dative "quirky" case marked direct internal object antecedent

$$
\begin{array}{lll}
\mathrm{Ja} & \text { velela } \mathrm{emu}_{\mathrm{i}} \mathrm{PRO}_{\mathrm{i}} \text { tancevat' } \text { golomu }_{\mathrm{i}} / & \text { golym }_{\mathrm{i}} . \\
\mathrm{I}-\mathrm{NOM} \text { ordered him-DAT to-dance naked-DAT/ } & \text { naked-INSTR }
\end{array}
$$

\section{Dative indirect internal object antecedent}

$$
\text { Ja dala emu } \mathrm{i}_{\mathrm{i}} \text { den'gi } \mathrm{PRO}_{\mathrm{i}} \text { tancevat' golomu } / \text { golym } \mathrm{i}_{\mathrm{i}} \text {. }
$$
I-NOM gave him-DAT money to-dance naked-DAT/naked-INSTR

Case agreement in these examples entails that the antecedent is already naked, and the speaker wishes him to dance as he is. The instrumental case entails that the speaker wishes the person in question to get naked and dance. ${ }^{10}$

\footnotetext{
${ }^{9}$ I assume, following Martin (1996: 176) that PRO gets null Case which, in turn, is a type of "chameleon" Case, in that it has no morpho-phonological properties of its own, but rather exhibits either default or inherited properties.
} 
The case marking possibilities in these examples have escaped notice before due to the types of examples that have attracted attention in the past. These examples have been ones like (37).

$$
\begin{aligned}
& \text { Ja poprosil Ivana }{ }_{\mathrm{i}} \quad \text { ne } \mathrm{PRO}_{\mathrm{i}} \text { prixodit' p'janym }{ }_{\mathrm{i}} /{ }^{*} \mathrm{p}^{\prime} \mathrm{janogo}_{\mathrm{i}} \text {. } \\
& \text { I asked Ivan-ACC NEG to-come drunk-INSTR/*drunk-ACC } \\
& \text { 'I asked Ivan not to come drunk'. } \\
& \text { (Franks 1995: 222) }
\end{aligned}
$$

The problem with this example lies in the event structure of the verb prijti 'to arrive'. Prijti 'to arrive' is an achievement in Russian. Achievements are almost instantaneous transitions. The instrumental case on predicate adjectives with achievements is strongly preferred. This preference is consistent with the hypothesis that the instrumental case focuses on the change of one state to another. Thus, the case most similar in aspectual meaning to the verb in the primary predicate is the case of choice.

That the instrumental case is linked to the [+eventive] feature of the secondary predicate finds support in two other phenomena in Russian: (1) the case marking in resultatives; and, (2), the distribution of NP secondary predicates (I use NP as catch all terminology for NPs and DPs). Although the distribution of resultatives is beyond the scope of this paper, it is noteworthy that they obligatorily occur with instrumental case marking on the predicate adjective, as seen in (38) below.

$$
\begin{aligned}
& \text { Alya pokrasila stol černym/ *černyj. } \\
& \text { Alya painted table-ACC black-INSTR/ *black-ACC } \\
& \text { 'Alya painted the table black'. }
\end{aligned}
$$

This fact is entirely in keeping with the analysis presented here. That is, resultatives involve the change of one state to another, i.e., they are eventive transitions. My analysis predicts that if a predicate adjective is eventive, it will occur with instrumental case marking. This predication is borne out.

If we posit that predicate adjectives have tense and aspect features, just like other [+verbal] elements, we have an explanation for an otherwise curious phenomenon, namely the fact that only adjectival phrases can occur with both case agreement and instrumental case marking in depictive secondary predicates, noun phrase predicates in Russian obligatorily occur with instrumental case marking, as the following examples show.

\footnotetext{
${ }^{10}$ Note that case agreement is no longer possible once the overt complementizer čtoby 'in order to' is present, as Franks (1995) noticed.

$$
\begin{array}{lll}
\text { On prišel, [cP čtoby PRO } & \text { tancevat' golym/ } & \text { *golyj] } \\
\text { He arrived in-order } & \text { to-dance drunk-INSTR/ } & \text { *drunk-NOM } \\
\text { 'He arrived/came in order to dance naked'. } &
\end{array}
$$

An explanation for this fact could lie in the status of the overt CP as a strong phase (for details, see Chomsky 1998, 1999). The derivation is built to CP and then sent to the interfaces. In the absence of any greater context for the predicate adjective that the higher clause might provide, the default interpretation of the predicate adjective is that it is eventive - since the event structure of the adjective is eventive - and the instrumental case is obligatory.
} 


$\begin{array}{ll}\begin{array}{l}\text { Ivan } \\ \text { Ivan-NOM }\end{array} & \begin{array}{l}\text { vernulsja domoj } \\ \text { returned home }\end{array} \\ \begin{array}{ll}\text { Ivan } & \text { vernulsja domoj } \\ \text { Ivan-NOM } & \text { returned home } \\ \text { 'He returned home a pauper'. }\end{array}\end{array}$

bednyj/ bednym. poor-NOM/ poor-INSTR

bednjakom/ *bednjak. pauper-INSTR/*pauper-NOM

In example (39) the secondary predicate is an adjective, while in (40) it is a noun phrase. Case agreement is only licensed on the adjective in (39). While it is clear that eventive noun phrases exist in language (noun phrases like 'the destruction (of the city), for instance), it is not so clear that noun phrase predicates have tense features. If only [+verbal] elements are able to manifest the contrast between tense and aspect, we have an explanation for why only adjectives show the case agreement versus instrumental case dichotomy, only adjectives have an interpretable tense feature in secondary predicates. ${ }^{11}$

\subsection{The Syntax of Depictives}

Thus, the syntax of depictive small clauses has to capture the following facts about English and Russian. In English, secondary predicates show two constraints: (1) the predicate adjective must be eventive; (2) both the primary predicate and the secondary predicate must be eventive-both must be transitions-with internal direct object antecedents (see section 3.3 for a discussion of indirect object antecedents). Predicate adjectives with subject antecedents are free to occur with any type of primary predicate. In Russian, predicate adjectives in depictive small clauses are free to occur with any type of primary predicate, regardless of the structural location of the subject or the object. The case marking on the predicate adjective, however, is sensitive to event structure. The syntax of depictive small clauses in Russian must capture the following two constraints: (1) case agreement occurs on the predicate adjective when the event time of the secondary predicate is identical to that of the primary predicate, a predicate adjective with case agreement is thus stative or noneventive; (2) a predicate adjective with instrumental case-marking never entails that the event time of the primary and secondary predicate is identical. Thus, a clause with a secondary predicate with instrumental case marking entails the occurrence of at least two events.

It is commonly thought that depictive small clauses are adjuncts, adjoined to the $\mathrm{V}$-bar, VP or vP level. I will suggest that in English, secondary predicate constructions with subject antecedents are adjunction structures, while secondary predicates with object antecedents are conjunction structures. These structures capture the fact that with object antecedents "likes co-occur with likes" (both the primary and secondary predicate must be eventive transitions), while with subject antecedents the secondary predicate is free to occur with a primary predicate of any event structure. Similarly, in Russian, case agreement occurs in a conjoined tense phrase, since the event time of the primary predicate is identical to that of the secondary predicate ("likes occur with likes"), while

\footnotetext{
${ }^{11}$ Note that this is a separate issue from whether a NP/DP arguments have an uninterpretable tense feature manifested as nominative case (see, for instance, Pesetsky and Torrego 2000). Crucially, there is little evidence that the noun phrase secondary predicate has tense features. Instead, the predicate NP is interpreted as eventive - a transition - and instrumental case marking is obligatory.
} 
the instrumental case occurs in an adjunction structure, since a predicate adjective with instrumental case marking entails the existence of a separate event, and it can occur with a primary predicate of any event type. That primary predicate transitions tend to favor secondary predicate transitions in Russian follows from the fact that the higher eventive primary predicate has scope (c-commands) over the secondary predicate. Note that the structures below are greatly simplified and only include relevant information for my analysis. They show movement of the nominative argument into Spec-TP to check its uninterpretable tense feature (see Pesetsky and Torrego 2000 for details). They do not show any other movement operations.

(41) English Subject Antecedents (adjunction structure)
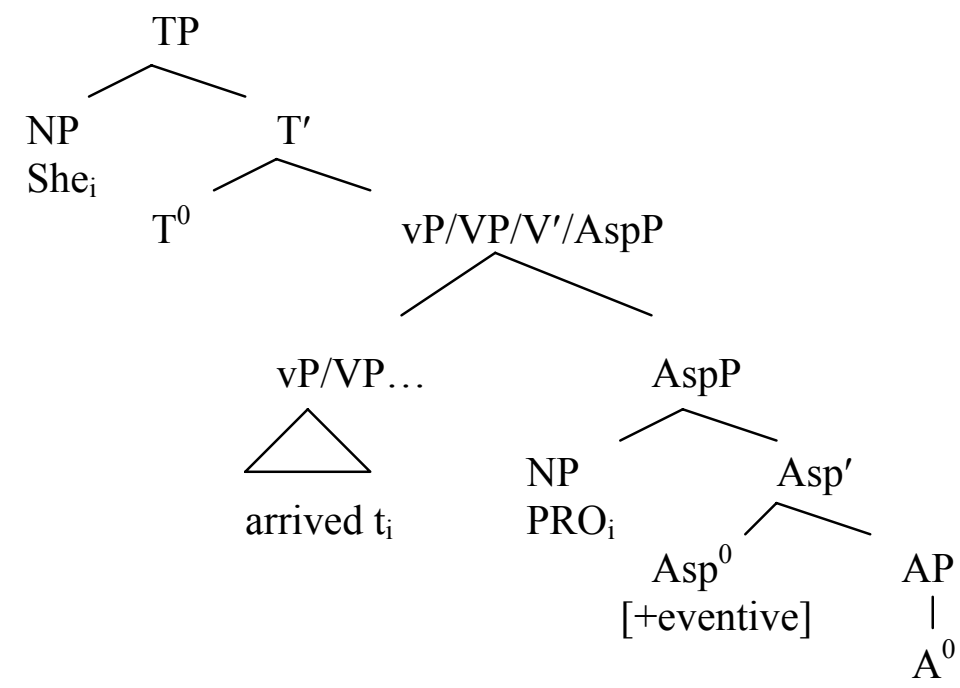

(42) English Object Antecedents (conjunction structure)

drunk

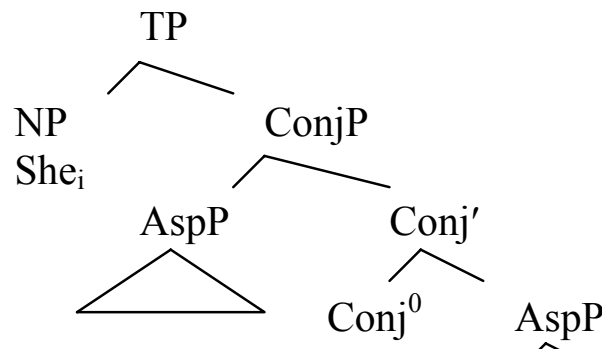

$\mathrm{t}_{\mathrm{i}}$ ate the meat $\mathrm{k}_{\mathrm{k}}[+$ eventive $] \sim$

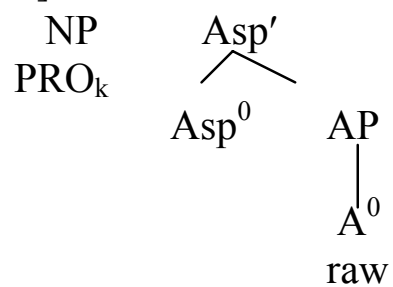

I leave open whether the secondary predicate adjoins to the vP/VP, AspP or v/V-bar level in (41). The adjunction site itself is not crucial in my analysis. What is important, is that 
predicate adjectives with subject antecedents constitute adjunction structures, while those with object antecedents are conjunction structures. I assume that the small clause is dominated by an aspectual phrase to account for the fact that only eventive predicate adjectives are possible in depictive small clauses. PRO is placed in the Spec of the functional category dominating the predicate adjective for theta reasons. I remain open, however, as to whether we really need PRO in secondary predicates. The (non-)existence of PRO is not crucial for my analysis. I place the (eventive) AspP in the primary predicate immediately below tense, i.e., dominating both vP and VP. This is purely for descriptive purposes and does not affect my analysis. It could alternatively be located between vP and VP (see Travis 2000 for such a suggestion). I take conjunction phrases to be asymmetrical binary-branching structures that obey the format of X-bar theory. Following Babyonyshev (1996), I also assume that ConjPs have the same distribution as the categories they dominate and are able to fulfill the same syntactic functions. The exact mechanism which ensures that the features of a ConjP and the features of the categories dominated by it match is not relevant for my analysis (the features may percolate up to the ConjP, or the ConjP may receive an arbitrary set of features, with some filter-like mechanism ruling out the constructions where its features and the features of the conjoined phrases do not match, as suggested by Babyonyshev 1996: 78). The crucial point here is that depictives constitute both adjunction and conjunction structures, i.e., not all depictive small clauses are the same.

If predicate adjectives with subject antecedents are adjunction structures, while predicate adjectives with object antecedents are conjunction structures, then we predict that movement out of the adjunction phrase should be possible, but movement out of the conjunction phrase should not, since movement is restricted by the Coordinate Structure Constraint (see Ross 1967). This prediction is borne out, as the following examples show.

She arrived drunk.

Drunk she arrived.

She ate the meat raw.

* Rawi she ate the meat .

In examples (43) and (44) the secondary predicate has a subject antecedent; it occurs in an adjunction structure and movement is possible. In (45), the predicate adjective has an object antecedent; it occurs in a conjunction structure and movement is not possible. ${ }^{12}$ Notice that movement of 'the meat raw' is ungrammatical, which supports the articulation of the noun phrase and predicate adjective as separate constituents.

*The meat raw he ate.

12 I assume that movement out of the first conjunct sounds considerably better than movement out of the second conjunct in (i) below, since while extracting one of the conjuncts out of a coordinate structure is ungrammatical ((ii) and (iii)) extraction of a subpart of one of the conjuncts is much more acceptable ((i) and (iv)) (see Babyonyshev 1996: 84 for details).

(i)

(ii)

(iii)

(iv)

\footnotetext{
?The meat he ate raw.

*Who did he and t Betty.

*Who did he see Betty and $t$.

?John who I bought a picture of $\mathrm{t}$ and a glass of water.
} 
What Secondary Predicates in Russian Tell Us

about the Link between Tense, Aspect and Case

(48) Russian Case Agreement (conjunction structure for both subject and object antecedents)

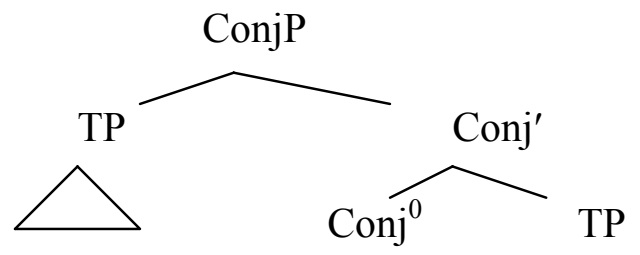

Ona-NOMi prišla $t_{i}\left[\mathrm{Te}_{1}=\mathrm{Te}_{2}\right]$

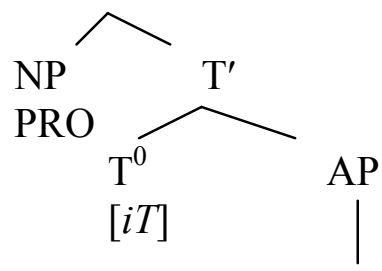

$$
\begin{aligned}
& \text { checking } \\
& \text { relationship }
\end{aligned}
$$

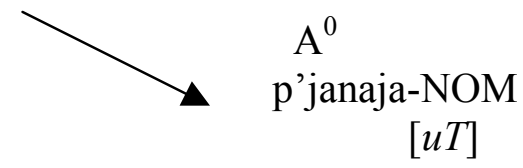

'She arrived drunk'

In this structure, a checking relationship is established between the $\mathrm{T}$ head (with interpretable tense $[i T]$ ) and the adjectival head of the secondary predicate. The case features of the predicate adjective are valued in situ. The predicate adjective's uninterpretable tense feature $([u T])$ —as manifested in agreement morphology-is deleted. The deleted feature disappears from the narrow syntax, allowing convergence at LF. Its morphological remnant, however, remains in the form of nominative case on the predicate adjective (case agreement). (Note $\left[\mathrm{Te}_{1}=\mathrm{Te}_{2}\right]$ means that the tense of the two events is identical.)

(49) Russian Instrumental Case (adjunction structure for both subject and object antecedents)

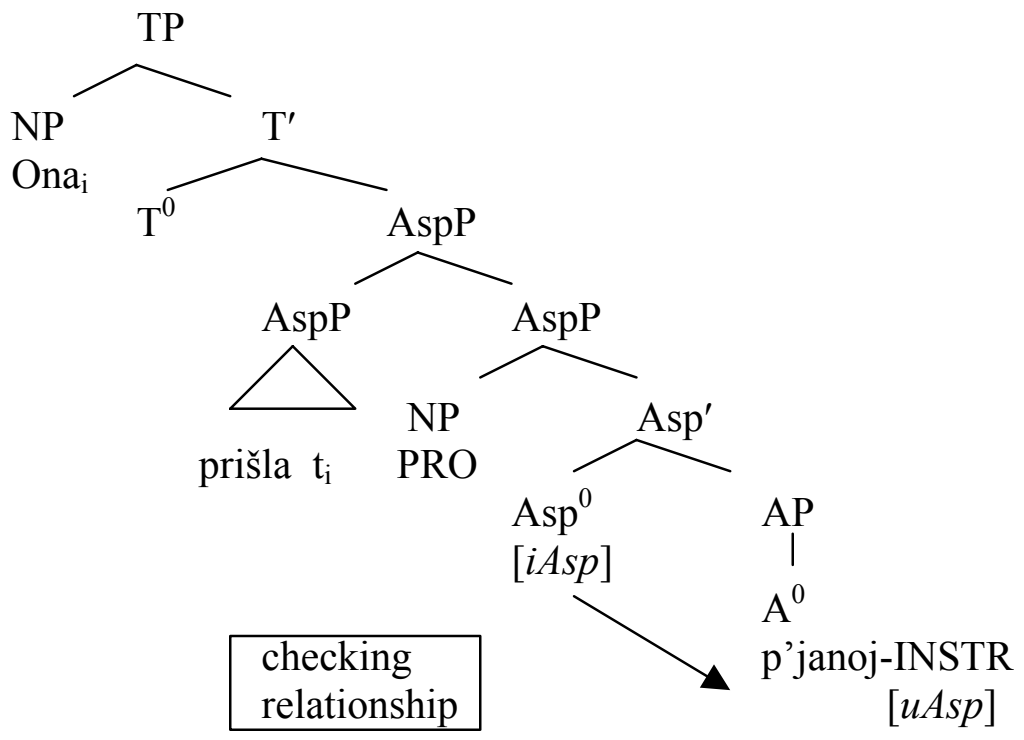


The checking relationship between the head of the aspectual phrase and the adjectival head works in the same manner outlined above for the tense head and the adjectival head in conjoined tense phrases in Russian.

These structures predict that movement will be possible in all depictive constructions in Russian. This prediction is borne out, as the following examples show.

$$
\begin{array}{lll}
\text { P'janye }_{i} & \text { my } & \begin{array}{l}
\text { tancevali } \mathrm{t}_{\mathrm{i}} \\
\text { Drunk-NOM }
\end{array} \\
\text { danced }
\end{array}
$$

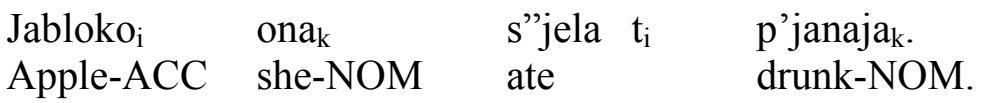

'The apple she ate drunk'.

$\begin{array}{lll}\mathrm{P}^{\prime} \text { janym }_{\mathrm{i}} \quad \text { druz'ja priveli ego }_{\mathrm{i}} & \text { domoj t }_{\mathrm{i}} . \\ \text { Drunk-INSTR friends brought him-ACC } & \text { home }\end{array}$

$\mathrm{Ego}_{\mathrm{i}} \quad$ druz'ja priveli $\mathrm{t}_{\mathrm{i}}$ domoj p'janym ${ }_{\mathrm{i}}$.

Him-ACC friends brought $t$ home drunk-INSTR

The crucial constraint on depictive conjunction phrases is that movement is not possible outside of the conjunction phrase itself. Thus, that (50) and (51) are possible tell us nothing, since the predicate adjective may have adjoined to the higher tense phrase, and may not have moved out of the conjunction phrase. The conjunction phrase dominates the entire clause in depictives, thus, if movement occurs to the left of the nominative subject, it does not mean that the moved element has moved out of the conjunction phrase, since the nominative subject is contained within the ConjP. As expected, movement out of the adjunction structure is licit, as (52) and (53) show. ${ }^{13}$

That "like TPs" only conjoin with "like TPs" finds support in the verbal system. Notice that if we conjoin two verb phrases with different event structures, the constructions are ungrammatical with identical time reference.

*He arrived and he sang.

*He walked along the shore and remembered the answer.

\footnotetext{
${ }^{13}$ Note that Bailyn and Rubin (1991: 106-107) claim that predicate adjective with instrumental case marking are not able to move. They provide examples like the following to support this claim.
}

(i) Golye/*Golymi, my tancevali. Naked-NOM/*naked-INSTR we danced.

Movement of predicate adjectives with instrumental case marking is possible and depends on a number of intonational, pragmatic and discourse related factors. Examples (52)-(55) are topicalized in the same way as English topicalized equivalents like 'Such behavior we do not tolerate in a civilized society'. 
Example (54) has an achievement conjoined with an activity. There is no way in which we can interpret the two conjuncts in this construction as identical in time reference, instead we interpret them as a sequence of events: 'he arrived and then he sang.' A similar state of affairs holds for (55), i.e., we do not interpret this construction as 'for the duration of his walking event along the shore, he remembered the answer.' Thus, secondary predicates in depictives follow the 'Coordination of Likes Constraint (CLC)' (See Chomsky 1957). The CLC in depictives is reminiscent of Schachter's (1977: 90) generalization that coordinate constructions must belong to the same syntactic category and have the same semantic functions, hence the ungrammaticality of (56) below.

*John and a stone broke the window.

It might seem counter-intuitive at first that there is more than one structure for depictive small clauses in languages. Upon closer inspection, however, it becomes clear that this belongs to a larger phenomenon, namely there are many different types of secondary predicate constructions that behave differently in different languages: complement small clauses like 'I consider him stupid', 'be' constructions (see footnote 4), statives with secondary predicates (see footnote 6). Complement small clauses in English, for instance, differ from their Russian counterparts, as the following examples show.

$$
\begin{aligned}
& \text { I consider him stupid. } \\
& \text { I consider him to be stupid. } \\
& \text { Ja sčitaju } \text { ego }_{\mathrm{i}} \quad \text { glupym }_{\mathrm{i}} /{ }^{*} \text { glupogo }_{\mathrm{i}} \text {. } \\
& \text { I consider him-ACC stupid-INSTR/*stupid-ACC } \\
& \text { * Ja sčitaju } \text { ego }_{i} \quad \text { byt' glupym. } \\
& \text { I consider him-ACC to-be stupid-INSTR }
\end{aligned}
$$

In English, we can insert the verb 'to be' to get the full clause equivalent of the small clause, while this is impossible in Russian. Furthermore, unlike depictives, instrumental case is obligatory on the predicate adjective in these constructions in Russian. Examples like (61) and (62) below show that depictives differ in various languages.

$$
\begin{aligned}
& \text { On prišel ko mne } \text { i }_{\mathrm{i}} \quad \text { p'janomu }_{\mathrm{i}} / \quad{ }^{*} \mathrm{p}^{\prime} \text { janym }_{\mathrm{i}} \text {. } \\
& \text { He-NOM came to me-DAT drunk-DAT/ *drunk-INSTR } \\
& \text { Ja } \quad \mathrm{S} \quad \text { nimi }_{\mathrm{i}} \mathrm{m}^{\prime} \text { ortvymi }_{\mathrm{i}} \text { razgovarival. } \\
& \text { I-NOM with them dead-INSTR spoke }
\end{aligned}
$$

In English a secondary predicate cannot adjoin to or conjoin with a prepositional phrase (or have an indirect object antecedent). In Russian, however, adjunction to or conjunction with a prepositional phrase is possible, as examples (61) and (62) show (see also section 3.3 on predicate adjectives with indirect object antecedents in Russian). We know that the predicate adjective is in fact adjoined (or conjoined) to the prepositional phrase and not 
the verb phrase in these examples, since under the movement test the adjective moves with its antecedent, unlike secondary predicates with direct internal arguments:

$$
\begin{aligned}
& \text { Ko mne }_{i} \quad \text { p'janomu }{ }_{i} \quad \text { on prišel. } \\
& \text { To me-DAT drunk-DAT he came. } \\
& \begin{array}{lllll}
\mathrm{S} & \text { nimi }_{\mathrm{i}} & \text { m'ortvymi }_{\mathrm{i}} & \text { ja } & \text { razgovarival. } \\
\text { With } & \text { them-INSTR } & \text { dead-DEAD } & \mathrm{I} & \text { spoke. }
\end{array} \\
& \begin{array}{lll}
\text { Mjaso }_{\mathrm{i}} & \text { syrym }_{\mathrm{i}} & \text { on s"jel. } \\
\text { Meat-ACC } & \text { raw-INSTR } & \text { he ate. }
\end{array}
\end{aligned}
$$

Examples (63) and (64) show that the predicate adjective can move with its antecedent in PPs, while (65) shows that this is not possible with a direct object antecedent.

Thus, the different behavior of secondary predicates with subjects and objects is part and parcel of a larger phenomenon: secondary predicates differ both within a language and across languages.

\section{Obligatory Case Agreement in Russian Depictives}

Thus far, I have focused on constructions in which both case agreement and instrumental case are possible on predicate adjectives. There are, however, three constructions in which case agreement is obligatory on the predicate adjective in Russian: (1) predicate adjectives with object antecedents with "quirky" dative or genitive case (objects with quirky instrumental case obviously occur with a predicate adjective with instrumental case marking); (2) adjectives with an antecedent contained within a PP; and, (3), adjectives with an indirect object (dative) antecedent. In what follows, I will suggest that case agreement in all three of these constructions is also linked to tense and aspect. Note that the following discussion is speculative and is part of a much larger project (Richardson in progress).

\subsection{Quirky Case Marked Objects}

The following examples, based on Bailyn and Rubin (1991) and Bailyn (1995), show that case agreement is obligatory with verbs like pozvonit'sja 'to phone' and boit'sja 'to fear', i.e., verbs that take obligatory dative and genitive case marked objects, respectively.

$$
\begin{aligned}
& \text { Ja pozvonila emu } \text { panomu }_{\mathrm{i}} /{ }^{\prime} \text { * }^{\prime} \text { janym }_{\mathrm{i}} \text {. } \\
& \text { I-NOM phoned him-DAT drunk-DAT/ *drunk-INSTR } \\
& \text { Polina boitsja Ivana } \text { Ivanogo }_{\mathrm{i}} / \text { *p'janym }_{\mathrm{i}} \text {. } \\
& \text { Polina-NOM fears Ivan-GEN drunk-GEN/ *drunk-INSTR }
\end{aligned}
$$

On the basis of examples like these (and the obligatory case agreement on the predicate adjective with internal indirect arguments discussed in section 3.3), Bailyn claims that 
true depictive secondary predicate adjective, which for him are adjuncts with instrumental case marking, occur in a null PredP with a PRO subject. He maintains that non-nominative or accusative arguments do not c-command this PRO subject (see Bailyn 2001 for details), and therefore are not the antecedents of adjunct secondary predicate constructions, but rather occur in appositive constructions. Thus, for Bailyn an adjunct predicate adjective with instrumental case marking is only licit when its antecedent ccommands the PRO subject of the secondary predicate.

Case agreement on the predicate adjective, however, appears to belong to a larger phenomenon linked to the role of the event structure of the verb phrase on the case marking of its arguments. Notice that in Russian, like Latin, Greek and Hebrew, quirky case marked objects are always so-called "affected patients". These arguments never play a role in the event structure of the verb phrase, i.e., they never delimit or "measure out" the event in any way (see Tenny 1994 for a discussion of the role of the direct internal argument in the event structure of the verb phrase). The Latin, Greek and Hebrew examples in the tables below are taken from Arad (1998: 77-78). I have added the Russian equivalents to Arad's table for comparison. Note that Hebrew marks the objects of these verbs with a locative preposition, be (at): kick at the ball, use at the knife, drive at a car, or le (to), al (upon).

(68) Quirky case marked objects

$\begin{array}{lllll}\text { English } & \text { Latin } & \text { Classical Greek } & \text { Hebrew } & \text { Russian } \\ \text { Help+acc } & \text { auxilior+dat } & \text { boetheo+dat } & \text { azar+le } & \text { pomogat'+dat } \\ \text { Use+acc } & \text { utor+abl } & \text { xraomai+dat } & \text { hiStameS+be } & \text { pol'zovat'sja+instr } \\ \text { Trust }+ \text { acc } & \text { fido }+ \text { dat } & \text { pisteuo+dat } & \text { bataz+be } & \text { doverjat'+dat } \\ \text { Rule+acc } & \text { dominor+abl } & \text { arxo+gen } & \text { maSal+al } & \text { pravit'+instr } \\ \text { Obey+acc } & \text { pareo+dat } & \text { peithomei+dat } & \text { ziyet+le } & \text { podčinjat'sja }+ \text { datv }\end{array}$

(69) Accusative case marked objects

$\begin{array}{lllll}\text { English } & \text { Latin } & \text { Classical Greek } & \text { Hebrew } & \text { Russian } \\ \text { Build }+ \text { acc } & \text { construo+acc } & \text { oikodomeo+acc } & \text { bana+acc } & \text { stroit'+acc } \\ \text { Write }+ \text { acc } & \text { scribo+acc } & \text { grapho+acc } & \text { katav+acc } & \text { pisat'+acc } \\ \text { Murder+acc }+ \text { occido+acc } & \text { apokteino+acc } & \text { racax+acc } & \text { ubivat'+acc } \\ \text { Eat+acc } & \text { edo }+ \text { acc } & \text { esthio+acc } & \text { axal+acc } & \text { est'+acc } \\ \text { Wash+acc } & \text { lavo+acc } & \text { luo+acc } & \text { raxac+acc } & \text { myt'+acc }\end{array}$

Arad (1998: 78) makes the strong claim that two-place predicates with "measuring objects" universally mark their object with accusative case. Two-place predicates with non-measuring objects may mark their object with either accusative, dative, ablative or genitive case, or by a preposition, depending on the particular morphological properties of the language. As these tables suggest, Russian seems to fit into this generalization. If we apply Dowty's in $x$ time (test for accomplishments) versus for $x$ time (test for activities), to any of these verbs - with their arguments - in English or Russian, it is clear that they are all activities or processes. This suggests that all of these verbs, even with their internal arguments present, are always processes, as the English examples below show. 
She ruled the country for two years/*in two years.

She obeyed him for a day/*in a day.

Unlike other processes or activities discussed thus far in this paper, the direct internal argument of these verbs can never delimit these events. Notice with activities like 'dance' and 'sing' that the direct internal argument can play a role in the event structure of the verb.

She danced for an hour/*in an hour.

She danced the jig for five minutes/in five minutes.

She sang for five minutes $/ *$ in five minutes.

She sang the song for five minutes/in five minutes.

Unlike (72)-(75), in (70) and (71) there is no possibility for these events, even with their internal arguments present, to be construed as transitions.

While the case marking of arguments is not the focus of this paper, what is interesting for my analysis of the case marking on the predicate adjectives that occurs with these verbs is that the potential ambiguity of other activities or processes to be interpreted as transitions appears to open the door for a secondary predicate to be interpreted as eventive and thus occur with instrumental case marking. Verbs with quirky case marked arguments are always pure processes and case agreement on the predicate adjective is always obligatory in Russian. Thus, the only possible secondary predicate structure with these verbs is a conjoined tense phrase, with the event time of the predicate adjective the same as that of the verb phrase with which it conjoins. This hypothesis is supported by the interpretation of these examples, i.e., example (66) above, for instance, is interpreted as 'I phoned him and at the time I phoned him, he was drunk'. ${ }^{14}$

\subsection{Prepositional Phrases}

As mentioned before, case agreement is obligatory in PPs (see examples (61) and (62)). That PPs (and CPs) are able to take care of the Case properties of their arguments, while NPs have to move, apparently for Case reasons, is common knowledge. The reasons for the dichotomy between PPs and CPs versus NPs, however, are still not clear. Recently, Pesetsky (comments in class) suggested that PPs might have some functional structure in them, and that perhaps this functional structure is a TP. If PPs (and CPs) have a TP that is able to enter into a checking relationship with the uninterpretable tense feature on its NP argument, this would explain why NPs contained within PPs do not have to move out of the PP in the narrow syntax in English. If Pesetsky's hypothesis is on the right track, we also have an explanation for why case agreement is obligatory in PPs in Russian: the only functional element in a PP is a TP (AspPs are absent). The secondary predicate conjoins with this TP and, as we know, conjoined TPs result in case agreement on the secondary predicate in Russian.

\footnotetext{
${ }^{14}$ This is a departure from Richardson (in press).
} 


\subsection{Internal Indirect (dative) Antecedents}

As mentioned previously, the predicate adjective with an indirect object antecedent exhibits obligatory case agreement in Russian, as (76) shows. As with PPs, secondary predication in English is not possible.

$$
\begin{aligned}
& \text { Ja dala emu } e_{i} \text { den'gi p'janomu } / \text { ' *p'janym }{ }_{i} \text {. } \\
& \text { I-NOM gave him-DAT money drunk-DAT/ *drunk-INSTR } \\
& \text { 'I gave him the money (when he was) drunk'. }
\end{aligned}
$$

The structural location of the dative indirect object, and its equivalent in English double object constructions, is highly controversial and far from resolved. The following hypothesis therefore does not claim to be anything but suggestive. If the PP does indeed have functional structure in both English and Russian, it is not unreasonable to consider that the PP "equivalent" in double object constructions (the indirect internal argument) is also dominated by this functional category, i.e., the indirect object occurs in Spec-TP, while the secondary predicate is merged as the complement of a null tense head (with interpretable tense features). If this functional structure is indeed tense, then we have an explanation for why we get case agreement in these constructions in Russian, i.e., the uninterpretable tense feature on the predicate adjective enters into a checking relationship with the interpretable tense feature on the $\mathrm{T}$ head. The different movement constraints in the following examples show that the predicate adjective with a dative indirect object antecedent forms a constituent with its antecedent, while the predicate adjective with a direct object antecedent does not.

$\begin{array}{lll}* \text { Mjaso } & \text { syrym } & \text { on s"jel. } \\ \text { Meat-ACC } & \text { raw-INSTR } & \text { he ate } \\ \text { Ivanu } & \text { p'janomu } & \text { ona dala den'gi. }{ }^{15} \\ \text { Ivan-DAT } & \begin{array}{l}\text { drunk-DAT } \\ \text { she gave money }\end{array}\end{array}$

These examples show that only the dative object and the secondary predicate form a constituent. Thus, like PPs the secondary predicate and indirect object form a constituent. As expected, the event time of the primary and secondary predicates is identical in (76) and (78).

\section{Conclusion}

In sum, this paper provided further support for the hypothesis that pure uninterpretable Case features can be eliminated from syntax. The different case marking possibilities on

\footnotetext{
${ }^{15}$ This example was not accepted by all my native informants. It is grammatical in what I term the "courtroom setting", i.e., it is the most neutral variant that a Judge could ask a witness or with which a witness could respond. All of my native informants did, however, agree that (77) is considerably worse than (78).
} 
predicate adjectives in depictive small clauses in Russian show that case is intimately linked to interpretable tense and aspect features. Case agreement is the uninterpretable counterpart of interpretable tense, while the instrumental case is the uninterpretable counterpart of interpretable aspect. Case agreement occurs in a conjoined tense phrase, instrumental case occurs in a conjoined aspectual phrase. English depictive secondary predicates with object antecedents also show a sensitivity to aspect, i.e., "transitions occur with transitions". Secondary predicates with subject antecedents do not show this sensitivity. Depictives with subject antecedents thus constitute true adjunction structures, those with object antecedents occur in a conjoined aspectual phrase. Thus, structural differences exist even within the class of depictive small clauses within a language and across languages, not to mention the differences that exist between other types of small clause constructions in a given language.

\section{REFERENCES}

Arad, M. 1998. VP-Structure and the Syntax-Lexicon Interface. PhD Dissertation. University College London. Distributed by MIT Working Papers in Linguistics.

Babby, L. 1991. Noncanonical Configurational Case Assignment Strategies. Cornell Working Papers in Linguistics 9:1-55.

Babby, L. and R. Freiden. 1984. On the Interaction of Lexical and Syntactic Properties: Case Structure in Russian. Cornell Working Papers in Linguistics 6: 71-105.

Babyonyshev, M. 1996. Structural Connections in Syntax and Processing: Studies in Russian and Japanese. Doctoral Dissertation, MIT.

Bailyn, J. and E. J. Rubin. 1991 The Unification of Instrumental Case Assignment in Russian. Cornell Working Papers in Linguistics 9: 99-126.

Bailyn, J. 1995a. A Configurational Approach to Russian "Free" Word Order. Doctoral Dissertation, Cornell University.

Bailyn, J. 1995b. Underlying Phrase Structure and 'Short' Verb Movement in Russian. Journal of Slavic Linguistics 3.1: 13-58.

Bailyn, J. and B. Citko. 1998. Case and Agreement in Slavic Predicates. Formal Approaches to Slavic Linguistics 7: 17-37.

Bailyn, J. 2001. The Syntax of Slavic Predicate Case, in ZAS Papers in Linguistics 22, ed. G. Jäger, A. Strigin, C. Wilder, and N. Zhang, 1-23.

Bruening, B. 1997. What Are Secondary Predicates? Evaluating the Syntax of Adjunction, in Proceedings of the Thirteenth Northwest Linguistics Conference, ed. L. Chang, E. Currie and K. Shahin, University of British Columbia, 49-65.

Carlson, G. 1977. Reference to Kinds in English. Doctoral Dissertation, University of Massachusetts at Amherst.

Chomsky, N. 1957. Syntactic Structures. The Hague: Mouton.

Chomsky, N. 1995. The Minimalist Program. Cambridge, Mass.: MIT Press.

Chomsky, N. 1998. Minimalist Inquiries: The Framework. MIT Occasional Papers in Linguistics 15. Cambridge, Massachusetts: MITWPL.

Chomsky, N. 1999. Derivation by Phase.Ms. MIT.

Chomsky, N. 2000. Minimalist Inquires. In Step by Step: Essays on Minimalist Syntax in Honor of Howard Lasnik, eds. R. Martin, D. Michaels and J. Uriagereka. Cambridge: MIT Press, 89-155.

Chvany, C. 1975. On the Syntax of Be-Sentences in Russian. Cambridge, Mass.: Slavica.

Collins, C. 1989. Conjunction Adverbs. Ms. MIT.

Dowty, D. 1979. Word Meaning and Montague Grammar: The Semantics of Verbs and Timers in Generative Semantics and in Montague's PTQ. D. Reidel Publishing Company, Dordrecht.

Franks, S. 1995. Parameters of Slavic Morphosyntax. New York, Oxford: Oxford University Press.

Hinterhölzl, R. 2001. Semantic Constraints on Case Assignment in Secondary Adjectival Predicates in Russian. ZAS Papers in Linguistics 22: 99-112. 
Jakobson, R. 1958/1971. Morfologičeskie nabljudenija nad slavjanskim skloneniem (sostav russkix padežnyx form). American Contributions to the Fourth International Congress of Slavists. Reprinted in Selected Writings 2: Word and Language, 154-183. The Hague and Paris.

Kiparsky, P. 1998. Partitive Case and Aspect, in M. Butt and W. Geuder, The Projection of Arguments, CSLI: Stanford, 265-308.

Krifka, M. 1991. Thematic Relations as Links between Nominal Reference and Temporal Constitution, in (eds) I. Sag and A. Szabolcsi, Lexical Matters. CSLI: Stanford, 29-54.

Martin, R. A. 1996. A Minimalist Theory of PRO and Control, Doctoral Dissertation, University of Connecticut.

Matushansky, O. 2000a. The Instrument of Inversion: Instrumental Case in the Russian Copula. WCCFL 19 Proceedings, 288-301.

Matushansky, O. 2000b. The Case of Aspect: Case and (Im)perfectivity in Russian Small Clauses. Paper published online, web.mit.edu/matushan/www/Downloads/ Case \%20of\%20Aspect\%201.0.pdf.

McNally, L. 1994. Adjunct Predicates and the Individual/Stage Distinction. WCCFL 12: 561576.

Nichols, J. 1981. Predicate Nominals: A Partial Surface Syntax of Russian. Berkeley: University of California Press.

Pesetsky, D. and E. Torrego. 2000. T-to-C Movement: Causes and Consequences. To appear in M. Kenstowicz,ed. Ken Hale: a Life in Language. MIT Press.

Pustejovsky, J. 1991. The Syntax of Event Structure. Cognition 41: 47-81.

Ramchand, G. C. 1997. Aspect and Predication: The Semantics of Argument Structure, Oxford, Clarendon Press.

Rapoport, T. R. 1991. Adjunct-Predicate licensing and D-structure. Syntax and Semantics 25: $159-187$.

Rapoport, T. R. 1993. Verbs in Depictives and Resultatives, in Semantics and the Lexicon, ed. J. Pustejovsky, 163-184.

Rapoport, T. R. 1999. Structure, Aspect, and the Predicate. Language3-4: 653-677.

Richardson, K. (in press). Small Clauses in Russian, in Proceedings of the First Harvard-MIT Student Conference (HUMIT 2000) MITWPL 40, ed. N. Lance, A. Costa, J. MartinGonzalez, O. Matushansky, and A. Szczegielniak.

Rosen, S.T. 1999. The Syntactic Representation of Linguistic Events. Glot International 4.2: 311.

Ross, J. R. 1967. Constraints on Variables in Syntax. PhD Dissertation. MIT.

Rothstein, S. 1983. The Syntactic Forms of Predication. Doctoral Dissertation, MIT.

Rothstein, S. 1992. Predication and the Structure of Clauses. Belgian Journal of Linguistics 7: $153-169$.

Rothstein, S. 2001. What are Incremental Themes? In G. Jaeger, et.al. ed. ZAS Papers in Linguistics 22: 139-158.

Safir, K. 1983. On Small Clauses as Constituents. Linguistic Inquiry 14: 730-735.

Shachter, P. 1977. Constraints on Coordination. Language 53: 86-103.

Stowell, T. 1981. Origins of Phrase Structure. Doctoral Dissertation, MIT.

Svenonius, P. 2001. unpublished ms. Case and Aspect.

Timberlake, A. 1982. Invariance and the Syntax of Russian Aspect, in Tense-Aspect: Between Semantics and Pragmatics, ed. P.J. Hopper, Amsterdam: Benjamins, 305-331.

Timberlake, A. 1986. The Semantics of Case in Russian Predicate Complements. Russian Linguistics 10: 137-165.

Tenny, C. 1994. Aspectual Roles and the Syntax-Semantics Interface. Dordrecht: Kluwer.

Tenny, $\dot{C}$. and J. Pustejovsky. 2000. Events as Grammatical Objects. Stanford: CSLI Publications.

Travis, L. 2000. Event Structure in Syntax. In eds. C. Tenny and J. Pustejovsky. Events as Grammatical Objects. Stanford: CSLI Publications, 145-186.

Vendler, Z. 1957. Verbs and Times. The Philosophical Review 66: 143-160.

Wade, T. 1992. A Comprehensive Russian Grammar. Blackwell: Oxford, UK.

Williams, E. 1980. Predication. Linguistic Inquiry 11: 203-237.

Williams, E. 1983. Against Small Clauses. Linguistic Inquiry 14: 287-308.

Kylie Richardson

Department of Slavic Languages and Literatures

Harvard University

12 Quincy St

Cambridge, MA 02140

skewes@fas.harvard.edu 